covered by a layer of endothelium. The other infarct, at apex of spleen, was exactly similar though only half the size. Condition of splenie artery and vein was not carefully investigated. In left pleural cavity was about two pints of thin hæmorrhigic fluid, without any naked-eye evidence of infection. Anterior border of corresponding lung was loosely adherent to parietal pleura, while base was firmly glued to upper surface of diaphragm. On separating latter from the lung two large areas of purulent lymph were exposed, and there was a most offensive odour recalling that in gangrene of lung. Substance of lower lobe carnefied, but no real consolidation; infective process was limited to pleural surface, having evidently extended up throu sh diaphragm Right lung and pleural cavity normal. Little blood-stained fluid in pericardium ; two hamorrhagic areas on surface of heart. The organ itself was enlarged, principally due to increase in size of right side which was crammed full of blood-clot. At extreme apex of righ ventricle was amall mass of tissue about size of walnut oval in shape and pinkish in colour, and entangled in bundles of heart muscle. Its central part was broken down into a little heart calty and flaby pale and flabby. Liver silghtly nutmeg and latty, but no infected areas, though th ol left lobe had forned part of wall of cavily containing in arct situated at upper pole of splesn. Tho lower four or fu feet of ileum and grearer part of colon were examined, but without discovering any trace of ulceration, recent or remote. Mesenteric glands only very moderately enlarged. No gross pathological changes in kidneys. Spesimens of pus were examined from $(a)$ mass in right ventricle; (b) fluid around spleen; and (c) that in lesser sac. They all gave- the coli reactions, probably indicating a general Bacillus coli infection.

I presume that in this case the course of events was thrombosis of some branches of the splenic vessels, followed by infarction, mild infection, and separation of the infarcted areas. It was probably when the latter process began that the hæmorrhage into the peritoneum occurred.

I am indebted to Colonel W. H. Starr for permission to use the notes of the first case, and to Lieutenant-Colonel J. R. Bond for a similar privilege with regard to the second, and to both for their interest and encouragement.

\section{PRIMARY SUTURE AND UNION OF OPERATION WOUNDS OF THE URINARY BLADDER.}

By A. RALPH THOMPSON, CH.M. MANGh., F.R.C.S. ENG., SURGEON IN CHARGE OF THE GENITO-URINARY DEPARTMENT, GUY'S HOSPITAI.

MUCH ingenuity has been exercised for some time now in devising more or Jess adequate schemes for dealing with an open suprapubic wound of the bladder. The wounds which result from operations of such a nature as suprapubic prostatectomy occur, of necessity, most frequently in middleaged or old people. In those cases of suprapubic operation in which some apparatus is fitted in order to prevent the running of urine and chemical fluids over the adjacent parts the skin is very liable to become exposed to the dangers of sepsis and trauma. On the other hand, in those cases in which no such measures are adopted the constant wetting of the dressing and consequent evaporation are liable to give the patient cold and retard his recovery.

Owing to the constant care exercised by my dressers at Guv's Hospital during the past four years I have been enabled to perform a number of operations, such as suprapubic prostatectomy, removal of a vesical growth, and retrograde catheterism, with primary suture of the bladder wall and superficial tissues.

Primary union occurring in bladder wounds of an operative nature offers such tremendous advantages over other methods of dealing with bladder wounds, that I am inclined to think it should be aimed at more frequently than it is. Cases of enlarged prostate and growth of the bladder which demand operation are put off frequently, in my experience, by both patients and their medical attendants, because they dread the inconvenience, labour, trouble, and danger involved by an open wound of the bladder. If, then, this difficulty of the open wound in a bladder can be in a reasonable number of cases overcome, we may expect to see enlarged prostates more frequently removed, and growth of the bladder extirpated, not so much for the purpose of averting a distressing and painful death, as is too commonly the case at present, as for rendering life pleasant and happy.

Method.

The method adopted for securing primary union in the wound following upon a suprapubic vesical operation in my cases is as follows.

After the actual disease is removed, such as an enlarged prostate or a vesical growth, steps are taken to control and prevent hæmorrhage. This is frequently quite trifting in amount, but is occasionally severe. The bladder is filled with gauze sponges which are saturated with hot boracic lotion at a temperature of $120^{\circ} \mathrm{F}$. After a little time the sponges are removed and liquor hamamelidis B.P. at a similar temperature is poured into the bladder and allowed to remain there. The quantity used is about 3 ounces. A coudé catheter is then inserted into the bladder vîa the urethra, especial care being now taken that the wound shall not be contaminated, the wound being covered with cyanide gauze. The point of the catheter is laid carefully in the bladder, about one-third up the vertical height of the bladder, and the position of the catheter at this level is carefully noted in its relations to the meatus for future use, as a catheter may slip even when tied apparently securely, and it is important that it should not do so unknown to the surgeon or his assistants. The bladder wound is then exposed, and sutures are applied as follows.

The two ends of the incision in the bladder are secured with Lane's forceps, and the edges slightly everted; fine catgut sutures are then placed through the muscle wall of the bladder, as close to the mucous membrane as possible, but not through it. Each suture is tied immediately after it is passed, but not cut until all are tied, as tension upon them helps to steady the bladder.

Some difficulty is usually experienced in inserting and securing the lower sutures, but this must be done as perfectly as possible. About six or seren sutures are thus inserted, tied, and cut. The sutured part is carefully palpated in order that any holes left by suturing may be discovered and closed. The fibrous and outer muscular coats of the bladder are now secured with thicker catgut sutures, inserted in the manner of Lembert, and carefully tied, especial care being taken, as before, with the lower part of the wound. The number of sutures is, as before, six or seven.

A small gauze wick is placed in the cave of Retzius, after this space has been carefully washed with boracic lotion. If the peritoneum has been retracted upwards it is brought back into its original position on the front of the bladder, or even " encouraged" down a little lower. I think it helps the incision in the bladder wall to heal more readily. The abdominal wall is then sewn up with two rows of catgut sutures, the deeper row being placed through the rectus and pyramidalis muscles and anterior layer of the rectal sheath on each side, and the more superficial row through the superficial fascia and skin. Care should be taken to place at least one superficial suture through the skin and subjacent tissue below the wick of gauze laid in the cave of Retzius, as the edges of skin are thus much more likely to unite when the gauze is removed than when the gauze has no suture below it. I believe this to be an important point. The usual gauze dressings are then applied and the catheter is secured in the urethra.

After-treatment of wound. - The patient is returned to bed and the after-treatment is begun at once. (I always now have a spinal anæsthetic given in these cases, so that any immediate treatment necessary is more easily performed than when the patient is unconscious.) The dresser of the case washes out the bladder with normal hot sodium citrate solution; this prevents any blood from clotting. The irrigation is done with the help of a special apparatus, which I always use for the irrigation of the bladder, and which consists of two funnels, each holding four ounces of fluid, connected by long indiarubber tubes to a $Y$ glass tube which in turn is connected up with the catheter by a short length of rubber tubing. There is in connexion with the two long tubes a double spring clip, so arranged that pressure opens one indiarubber tube and at the same time closes the other, or vice vers $\hat{\alpha}$; and thus first the clear irrigating fluid only mixes in very small quantity with the fluid from the bladder; and, secondly, the amount of fluid from the bladder can be easily compared with the amount injected. Care is taken that only four ounces of fluid are introduced, and drawn off, at each irrigation. Between the intervals of irrigation the catheter is connected with a drainage-tube having as long a drop as possible. These irrigations are continued at gradually lengthening intervals until the washings are free from blood, which usually happens within three days. For the next two or three days boric acid lotion is substituted for the sodium citrate solution, which has done its work in preventing clotting of the blood in the bladder. The gauze wick is removed upon the second day. The catheter is removed at the end of a week or 10 days, and the patient allowed up at the end of 14 days without a catheter. The sutures are removed after 14 days. 
Results.

The results of this method of treating operation wounds of the bladder are detailed in the accompanying table of 13 cases. Kiven where a small fistula formed, it was quite small and rapidly healed, and in the case which was, relatively speaking, a failure, I do not regret having attempted primary union, as the open wound healed up remarkably quickly-I fancy much more quickly than if primary union had not been attempted.

Summary of Cases of Primary Union after Operation upon Urinary Bladder.

$\begin{array}{llllll}\text { Total number of cases ... } & 13 & \text { Partial success ... } & \ldots & \ldots & 2\end{array}$ \begin{tabular}{ll|llllll} 
Average age of patients... & 58 & Success & $\ldots$ & $\ldots$ & $\ldots$ & $\ldots$ & 10
\end{tabular}

These cases have been reported by me as, although they are too few to form general conclusions from, they do show that much of the trouble incident to an open bladder wound may be overcome by obtaining primary union. I do not at present attempt primary union in cases in which (1) there is marked cystitis, (2) there is considerable renal insufficiency, (3) bleeding cannot be sufficiently arrested at the time of operation, or (4) too much unavoidable damage to the bladder wall has been done.

The good result indicated in the table is due chiefly to the assiduous after-care of my dressers, who, however, realise that, after the first two or three days, there is infinitely less trouble involved than when the wound is left open. Moreover, one is greatly assisted in these cases by the temporary partial suppression of renal activity which takes place, as I think, immediately after a major operation upon the bladder, and which may last for as long as 24 hours. If, however, the success of these operations, as indicated below, is in future practice justified, then it may be said that bladder surgery has advanced a considerable step forward, and been robbed of half its terrors.

\section{Group I., Stricture of Urethra.}

Cass 1.-Male, 67. ? Enlarged prostate. (Dr. L. G. Reynolds, Balham.) Suprapubic cystotomy. General anæathetic, Primary suture of bladder and abdominal wall. Primary union. Discharged well from hospital three weeks after operation. Oystoscoped five weeks after operation. Greyish-white slough seen at fundus of bladder. Small urinary fistula formed, which healed up in ten days time. Partial success.

CASE 2.-Male, 41. Impassable stricture. (Sir A. Fripp.) Suprapubic cystotomy. Retrograde catheterism. Internal urethrotomy. General anæsthetic. Primary suture of bladder and abdominal wall Discharged within four weeks of operation. Union perfect. No. 14 English catheter is being passed without difficulty. Success.

Group II., Suprapubic Exploration of Bladder.

CASE 1.-Male, 35. ? Vesical neoplasm; none found. Suprapubic cystotomy. Primary suture and union of wound. Deep part of wound closed firmly. Slight retraction of skin edges. Delayed union of skin, but no urinary fistula. Partial success.

$$
\text { Group III., Growth of Bladder. }
$$

Cass 1.-Male, 37. Papilloma of bladder. Suprapubic cystotomy. Removal of growth. Primary suture and union. Discharged well at Removal of growth. Primary suture and

CASE 2.-Male, 69. Large papilloma at base of bladder. (Sir A

Fripp. Suprapubic cystotomy Remo at base of bladder. (Sir A. Fripp.) Suprapubic cystotomy. Removal of growth. Diathermy of base of bladder by Dr. C. E. Iredell. Primary suture and union of
wound. Hæmatoma formed in perineum : this in part broke down, and wound. Hæmatoma formed in perineum; this in part broke
small, quite temporary, perineal sinus formed. Success.

CASE 3.-Male, 57. Papilloma of bladder. Suprapubic cystotomy. Spinal anæsthesia. Removal of growth. Much bleeding and clotting of blood. Bladder wound reopened and left open eighth day. Recovery. Failure.

Group IV., Uncomplicated Enlarged Prostate.

CASE 1.-Male, 56. (Major Wallace Kemp, R.A.M.C. T., Kènsington.) Enlarged prostate. Suprapubic cystotomy; general anæsthetic. Removal of prostate. Primary suture and union. No complications. Success.

CASE 2.-Male, 70. Very much enlarged prostate. Suprapubic cystotomy. Spinal anesthetic. Removal of prostate. Primary suture and union. No complications except slight orchitis. Success.

CASE 3.-Male, 65. Enlarged prostate. Suprapubic cystotomy. Spinal anæesthetic. Removal of prostate. Primary suture and union. Spinal anesthetic. Removal

CASE 4.-Male, 64. (Mr. H. J..B. Cane, Belvedere.) Enlarged prostate. Suprapubic cystotomy; spinal anæsthetic. Removal of prostate. Primary suture and union. No complications. Success.

CASE 5.-Male, 65. (Mr. H. Cardin, Ingatestone.) Enlarged prostate. Suprapubic cystotomy ; spinal anesthetic. Removal of prostate. Primary suture and union. No complications. Success.

CAsE 6. - Male, 66. (Dr. J. Steed, Staunton.) Patient very fat man. Fnlarged prostate. Suprapubic cystotomy; spinal anæsthesia. Removal of prostate. Primary suture and union. No complica
Success.
Group V., Enlarged Prostate with Vesical Calculus.

Case 1.-Male, 64. (Mr. Cane, Belvedere.) Bnlarged prostate. Suprapubic cystotomy : spinal anesthetic. Removal of prostate and three Iarge stones. Primary suture and union. No complications. Success.

\section{Olinical a dotes: \\ MEDICAL, SURGICAL, OBSTETRICAL, AND THERAPEUTICAL.}

\section{A CASE OF SYPHILITIC PERIPHERAL} NEURITIS.

By Harold E. Thorn, M.B., B.S. Lond., M.R.C.S. ENG.,

TEMPORARY SURGEON, ROYAL NAVY.

TeE following case is of some interest as far as, the accurate diagnosis is concerned.

The patient, a signalman, aged 25, in H.M.S.-- in the Eastern Mediterranean Squadron, joined this ship on July 21st, 1916, from Malta. Six days later I saw him, and he gave me the following history. He had had primary and secondary syphilis in March, 1916, having been infected at Malta, and had been treated in Bighi Hospital, Malta, with two injections of galyl, one in April and the other in May. He had no mercury, but thought that he had had potassium iodide for a few days. He was examined generally on July 27th, and no signs of syphilis were found. Mercury in the form of cream (11 gr.) was injected into the buttock and this treatment was continued weekly until Oct. 12th. Only eight days after the first injection (August 4th) the patient complained of weakness in the right arm and hand. On examination a typical right main-en-griffe was found; the right hypothenar eminence was definitely wasted and there was cutaneous anæsthesia over areas corresponding to part of the distribution of the sixth and eighth cervical and first dorsal nerves to the right forearm and hand. Massage and passive movements were ordered to be applied to th 2 right arm daily and he was given light duty. A fe $i$ terra. cotta spots were found on the trunk; these were not very definite and nothing further developed in that region. No salivation, diarrhoea, or vomiting was present. No sign or history of alcoholism or injury could be found, and as regards the former the man had not been ashore, so was exceedingly unlikely to have had excess of aleohol. No swelling in the neck or axilla could be detected; there was no blue line on the gums or other sign of plumbism; no history suggested diphtheria, influenza, tubercle, enteric, or malaria, nor was dengue, Malta fever, beri-beri, or leprosy apparent. On August 7 th and 8th the patient was further examined and bosides the signs found on the 4th the following details were noted: Weakness of the extensors of the right wrist; anæsthesia over the right forearm and hand, analgesia being the most extensive (see Figs. 1 and 2 ); touch and temperature not lost

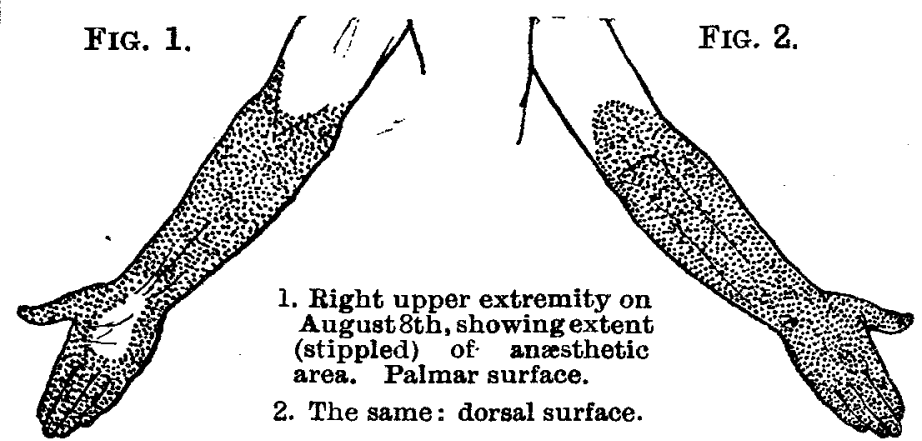

quite so extensively; relative hot and cold sensation unimpaired over rest of arm ; circumference of right forearm a quarter of an inch smaller than left at its largest diameter, half an inch smaller at the middle. (The patient is righthanded.) The right supina tor jerk was absent; the left present Both knee-jerks were present and the rest of the central nervous system was normal. No spinal disease could be detected. The patient complained of pain, and there was a discharge from the right ear; acute otitis media was found on that side. He stated that he had had recurrent similar attacks in the same ear throughout his life. Examination of the urine showed it to be neutral; specific gravity 1014 ; no albumin or sugar. On August 19th the membrana tympani of the right ear had healed com. pletely after treatment locally by syringing with izal, drachm to the pint, and the application of boric powder. Power in the right hand was slightly better. On the 22nd a note was made that sensation was improving. 31st: Sensation over ulnar and median nerve distribution improving. Sensation remained impaired over the dorsal area supplied by the radial (see Fig. 3). Sept. 2lat : Analgesia 